\title{
NEW PARADIGM IN ACCOUNTING INFORMATION SYSTEMS - THE ROLE OF THE LATEST INFORMATION TECHNOLOGY TRENDS
}

\author{
Zoran Minovski, \\ Faculty of Economics - Skopje, Ss Cyril and Methodius University \\ zoran.minovski@eccf.ukim.edu.mk \\ Bojan Malchev \\ Faculty of Economics - Skopje, Ss Cyril and Methodius University \\ bojan.malcev@eccf.ukim.edu.mk \\ Todor Tocev \\ Faculty of Economics - Skopje, Ss Cyril and Methodius University \\ todor.tocev@eccf.ukim.edu.mk
}

\begin{abstract}
The purpose of this paper is to identify the impact and benefits of the latest information technologies on Accounting Information Systems (AIS). Taking into account the numerous papers related to new technologies and their application in the accounting profession within Industry 4.0, and conducted survey about perception of practitioners in Republic of North Macedonia, this paper summarizes the characteristics and key benefits of some of the new technologies for the functioning of AIS in the digital age. First of all, the evolution of AIS is elaborated, based on theoretical and empirical analysis of the accounting process from the appearance of the first AIS up to nowadays' services and techniques available for supporting the accounting function. The first technology to be elaborated is Big Data and its potential to change the business landscape, especially in the field of automating operation processes, customer engagements, and predictive decision-making process. Secondly, the Blockchain Technology as an example of Distributed Ledger Technology (DLT), which adoption brings new possibilities in eliminating or redefining the role of entities external to the company. Cloud Computing i.e. Cloud Accounting is the third technology which is elaborated in this paper through the services it offers on the cloud, especially the way AIS process, store and backup the sensitive and confidential data. Last but not least, Artificial Intelligence (AI), a technology that could change the professional services, the need, and opportunities that are provided for a solution to the current accounting issues. In summary, taking into account the relevant literature and the perception of the respondents-practitioners, increased use of these technologies is necessary because their application reduces costs; increases transparency and confidence in information; flexibility, i.e. no time and space restrictions on their use, etc., which is especially useful in the current state of Pandemic, caused by the virus COVID-19.
\end{abstract}

Keywords: Accounting Information Systems, Big Data, Blockchain, Cloud Computing, Artificial Intelligence.

JEL classification: M40; M41

\section{INTRODUCTION}

Ever since the beginning of industrialization, technological leaps have led to paradigm shifts which today are ex-post named "industrial revolutions": in the field of mechanization (the so-

http://doi.org/10.47063/EBTSF.2020.0004

http://hdl.handle.net/20.500.12188/9694 
called 1st industrial revolution), of the intensive use of electrical energy (the so-called 2nd industrial revolution), and the widespread digitalization (the so-called 3rd industrial revolution). Based on an advanced digitalization within factories, the combination of Internet technologies and future-oriented technologies in the field of "smart" objects (machines and products) seems to result in a new fundamental paradigm shift in industrialization(Lasi et.al, 2014). Industry 4.0 has been considered as a new industrial phase in which new information technologies are converging to provide digital solutions for business. The power lays in the network of smart machines that are interconnected and can create, analyze, and share information (Marr, 2018). The McKinsey Global Institute estimates that "It's happening 10 times faster and at 300 times the scale than the Industrial Revolution in the early 19th century" (Hoffman, 2017). The accounting process is based on recording financial information along with storing, sorting, analyzing, summarizing, and interpreting information in various reports and analyses towards internal and external users. The accounting system has a key role in providing the financial information used in the decision-making process. Considering the large volume of information and the necessary time to process it, accounting software became a very useful tool for accountants to do their job faster and more efficiently. Although accounting software has been around for decades, it has continued to develop its potential over the years; it has become highly sophisticated and this evolution marches on (Dimitriua \& Mateia, 2015). As the digital revolution is shaping the field of accounting and auditing both current accounting and auditing professionals as well as students and professors at universities must fundamentally understand all of the information technologies that affect the accounting information systems. Accounting, the art and science of measuring business performance, has evolved with business, more so with information technology. Databases and data warehouses, specialized accounting software and Enterprise Resource Planning (ERP) systems, Local Area Networks (LANs), and Wide Area Networks (WANs), among other things, have left their mark on accounting theory and practice. Data-entry mechanisms, data storage and processing mechanisms, end reports, internal controls, audit trails, and skillsets for accountants have been in continual flux for the past several decades (Deshmukh, 2006).

\section{EVOLUTION OF AIS}

AIS is responsible for the collection, storage, and processing of financial and accounting data that is used for internal management decision making, including nonfinancial transactions that directly affect the processing of financial transactions (Belfo \& Trigo, 2013). Typically an AIS is composed of three major subsystems: (1) Transaction Processing System (TPS) that supports daily business operations; (2) General Ledger System and Financial Reporting System (GLS/FRS) and (3) the Management Reporting System (MRS) (Hall, 2011). There are six components of an AIS: (1) people; (2) procedures and instructions; (3) data 4) software; (5) information technology infrastructure and (6 )internal controls and security measures that safeguard AIS data (Romney, 2018). Accounting information systems have three basic functions: the first function of an AIS is the efficient and effective collection and storage of data concerning an organization's financial activities; the second function of an AIS is to supply information useful for making decisions; the third function of an AIS is to make sure controls are in place to accurately record and process data (AccountingEdu, 2020). The Evolution of The Accounting Information System Model consists of: 1. Manual Process Models: the oldest and traditional forms of accounting systems, forming physical events, personal resources that characterize most business processes. 2. Flat File Model: describes an environment where individual data files do not relate to other files. End-use has data files and does not use it with other users. 3. Database System Model: describes the centralization of company data into a shared database that is shared with all users. Access to data resources is 
controlled through a database management system (DBMS). 4. REAREA system model. It is an accounting framework for modeling resources, events (activities), and agents (actors) companies that are very important, and relationships between them. 5. ERP system model. ERP is an information system model that allows companies to automate and integrate various key business processes besides that a variety of traditional functional barriers can be overcome because this system facilitates the existence of shared data among all users in the company (Hall, 2019).

\section{BIG DATA}

In recent years, "big data" has received increasing attention from accounting practice because more data have been collected by organizations in the recent two years than in the previous 2000 years (Syed et al., 2013). Big Data refers to data sets that are so voluminous and complex that traditional data processing application software is inadequate to deal with them. IBM data scientists break Big Data down into four dimensions: 1. volume (quantity of data), 2. variety (different sources of data), 3. velocity (the speed of data), and 4. veracity (the uncertainty of data) (CPA Canada, 2019). In organizational settings, disruptive phenomena significantly alter value chains. Indeed, big data and its four "V" characteristics have had a profound impact on the people, processes, and technologies related to the information value chain. First, the new value chain involves a different set of people, processes, and technologies. While IT is known to exist in a constantly changing landscape, we can see the accompanying changes to the people and processes attributable to big data as a disruptor. Second, there is greater amalgamation of technologies into "platforms" and processes into "pipelines" in the value chain's knowledgederivation phase. Third, we see greater reliance on data scientists and analysts across all stages of the value chain to support self-service and realtime decision making (Abbasi et al., 2016). Data service companies specializing in collecting and evaluating designated data from various sources could emerge, such that big data pertaining to the fair value of assets and liabilities can mitigate subjective assumptions in fair value estimates (Hong Kong Institute of CPA, 2017). Big Data can exist as large structured data (e.g., data that fit into a defined schema, such as relational data), semi-structured data (e.g., data that are tagged with XML), unstructured data (e.g., text and video), and multi-structured data (e.g., integrated data of different types and structural levels). Unstructured data represent the largest proportion of existing data and the greatest opportunity for exploiting Big Data (Moffitt \& Vasarhelyi, 2013). Unstructured information is $90 \%$ of Big Data and is 'human information' like emails, videos, tweets, Facebook posts, call center conversations, mobile phone calls, website clicks (Syed et al., 2013).

\subsection{Big data opportunities and challenges}

The management of big data for accountants and finance professionals means more than 'gamechanging' opportunities. It means new challenges, as the importance of big data in business grows, they will need to find ways to measure its intrinsic value as an organizational asset (ACCA\&IMA, 2013). Patterns and information that were previously hidden in large quantities of data (because extracting them required too much work, would take too long, or was too expensive) can now be exploited in many ways. Accountants and finance professionals have already spotted the potential. In the 2012-13 ACCA-IMA survey $78 \%$ of respondents said that they expect widespread adoption of the data analysis tools that can be used to collate, manage and analyze large amounts of structured and unstructured data (ACCA\&IMA, 2013). Other research indicates that $80 \%$ of enterprises in the developed world are already investing at least some part of their budget in big data, and the role of big data is expected to increase over the next five years as new and existing systems further exploit its potential (Visiongain, 2013). The 
analysis of Big Data moves the information professional away not just from historical to realtime processing but also from a focus on samples. Entire data sets become analyzable to determine unknown unknowns (Bhimani \& Willcocks, 2014). Data is increasingly used to drive operating efficiencies. Some of the benefits are seen in the retail sector, where real-time analytics are helping companies keep pace with customer demand and reduce logistics and distribution costs. Big data is more than a business tool used for competitive advantage. The key concept here is that accountants and finance professionals who develop metrics for big data could differentiate themselves in the marketplace. Recent research has found that $20 \%$ of large companies already class data as an asset on their balance sheets - and that for companies with more than 10,000 employees, the figure rises to 30\% (Dynamic Markets, 2012). Providing data valuation services could be a significant opportunity - and an important differentiator - for accountants in the future. Yet valuing data is fraught with difficulty.

\section{BLOCKCHAIN}

At its most basic level, blockchain is literally just a chain of blocks, but not in the traditional sense of those words. When we say the words "block" and "chain" in this context, we are actually talking about digital information (the "block") stored in a public database (the "chain"). "Blocks" on the blockchain are made up of digital pieces of information. Specifically, they have three parts: 1) Blocks store information about transactions like the date, time, and value; 2) Blocks store information about who is participating in transactions; 3) Blocks store information that distinguishes them from other blocks (Reiff, 2020). The Blockchain can be seen as the distributed, decentralized, transparent, and chronological database of transactions, sometimes also called the Ledger. The data in the blockchain (e.g transactions) is divided into blocks. Each block is dependent on the previous one. The system in which a blockchain serves as the database comprises of nodes or workers. These workers are responsible for appending new blocks to the blockchain. A new block can only be appended after all nodes in the system reach a consensus, i.e all agree that this block is legitimate and contains only valid transactions. How the validity of transactions is determined and how the nodes compute new blocks, is regulated by the protocol. Blockchain is shared among all nodes in the system; it is monitored by every node and at the same time controlled by none. The protocol itself is responsible to keep the blockchain valid (Inghirami, 2019). Blockchain is the most common application of Distributed Ledger Technology (DLT). DLT uses cryptographic tools and a distributed consensus process to create a significant innovation in traditional record keeping. It has three main features: 1) Veracity - multiple copies (as opposed to a single copy) of the complete historical record of ledger entries are each verified by consensus; 2) Transparency - it is a public record of activity that can be seen by all market participants and 3) Disintermediation - it operates using a peer-to-peer network, rather than requiring a specific central organization (Chartered Accountants A\&NZ, 2017). It is common knowledge that the Internet is a key tool in the digitalization process. Tapscott indicated Blockchain to be the "World Wide Ledger", enabling many new applications beyond verifying transactions such as in smart deeds, decentralized and/or autonomous organizations/government services, etc. (Tapscott \& Tapscott, 2016). The most common fields of applications, of the Blockchain, are: Smart contracts, domestic payments, international payments, trade finance, and capital markets (Frøystad \& Holm, 2020). All of these areas of application of blockchain technology can be systematized into three main categories (Swan, 2015): 1) Blockchain 1.0: Currency - The currency and services associated with money transfers such as payment mechanisms and remittance services. 2) Blockchain 2.0: Smart contracts - a 'smart contract' is a computer protocol intended to digitally facilitate, verify, or enforce the negotiation or performance of a contract. Smart contracts allow the performance of 
credible transactions without third parties. 3) Blockchain 3.0: Areas in government, health, science, etc. - it is a Blockchain application system beyond financial markets and covers government, art, culture, and science. An example of 3.0 applications are Blockchain voting systems.

\subsection{Blockchain Adoption in AIS}

Blockchain ledger-based technology, i.e. GLT can simplify the procurement process because it enables secure recording of transactions in a way that can lead to unprecedented transparency and increased operational efficiency (Tysiac, 2017). Many "big players" like Microsoft, SAP, or Deloitte are starting to offer solutions that incorporate Blockchain-related technologies, typically based on a "Blockchain as a Service (BaaS)" approach as those that we have seen (Inghirami, 2019). Blockchain as a Service (BaaS) \& Real-time Blockchain Accounting System (RBAS) - Claimed benefits of Blockchain include offering business value and efficiency gains by, for example, assisting compliance, asset tracking, supply chain management, and generally displacing intermediaries. The focus is particularly on multi-party scenarios (across organizations, departments, individuals, etc.), where the ledger provides a transparent and reliable source of facts across administrative domains. The precise nature of a BaaS deployment depends on the service provider, application specifics, and the customer goal.Several IT solution companies provide BaaS solutions, like Microsoft, Deloitte, Peer Ledger, PayStand, Blockstream, Blocko, BitSE, SAP Cloud Platform Blockchain, etc. (Patrizio, 2018). Real-time Blockchain Accounting System (RBAS) is a software solution that enables transactions of currency, financial derivatives, and other digital documents between two or more counterparts, stores the transaction data in cryptographically protected blocks whose integrity is verified through the process of mining, and allows the composition of financial statements at any time (Potekhina \& Riumkin, 2017). Database, ERP and Blockchain Databases are the best explored and widespread transaction recording and organizing applications. Specifically, distributed databases are more comparable with blockchain as both systems rely on multiple computers for operation and maintenance procedures. Peters and Panayi (2016) argued that blockchain helps to avoid the conflicts that occur when multiple modifications are made simultaneously by different computers within the distributed database system. They also mention other benefits of incorporating blockchain into such systems. These benefits include the ability to create self-enforcing contracts, as well as to ensure the security, confidentiality, and integrity of the data stored in its ledger (Peters \& Panayi, 2016). ERP systems are among the most important innovations that incorporate database usage. An ERP system is prepackaged business software that provides an integrated solution for the organization's information processing needs.Blockchain is considered a new type of database that has the potential to either play the role of the accounting module in an ERP or be used in conjunction with the existing accounting information system. Unlike a regular ERP that is usually organized in a centralized architecture, blockchain distributes the power of transaction verification, storage, and organization to a group of computers (Dai \& Vasarhelyi, 2017).

\subsection{Blockchain opportunities and challenges}

In their 2017 Harvard Business Review article "The Truth About Blockchain", professors Marco Iansiti and Karim Lakhani described how it is not a disruptive technology but rather a "foundational" one with the potential "to create new foundations for our economic and social systems". They also suggest that its adoption will be "gradual and steady", a finding in line with the Association of International Certified Professional Accountants 2018 Future of Finance survey. Only $2 \%$ of those surveyed said their finance teams were currently using blockchain, and only $9 \%$ were investing in it for the medium term. This shows a huge potential 
for growth in this area (Rowe, 2019). The above-mentioned literature highlights characteristics, merits, and advantages deriving from the adoption of DLT systems, i.e. Blockchain technology.

\section{THE IMPACT OF CLOUD COMPUTING ON AIS}

Cloud computing is becoming a powerful and valuable tool for companies and has been identified as one of the key technology trends that accountants should stay abreast of over the next decade (Corkern et al., 2015). According to a report issued by the Committee of Sponsoring Organizations (COSO) of the Treadway Commission in 2012, authors defined Cloud computing as a computing resource deployment and procurement model that enables an organization to obtain its computing resources and applications from any location via an Internet connection. Depending on the cloud solution model an organization adopts, all or parts of the organization's hardware, software, and data might no longer reside on its technology infrastructure. Instead, all of these resources may reside in a technology center shared with other organizations and managed by a third-party vendor. Unlike traditional models where software applications are installed on the company's computers or servers, with cloud computing, software applications are accessed through an Internet connection and are rented rather than purchased. Armbrust, et al., (2010) in their paper state that cloud computing technology covers informatics applications provided through the internet, as well as the hardware and software equipment used in data centers for supplying these services. Generally, the accounting system gives the business a way to view and analyze financial information and provide: collecting and storing data, information useful for decision making, controls to ensure the accurate recording and processing of data, forecasts of future conditions such as projected financial statements and financial budgets.

Traditionally two types of accounting systems are known: a) accounting system locally installed on the company's computers, and b) web-based accounting software installed on a server. Today web-based accounting systems are closely related to the new cloud computing approach (Christauskas \& Miseviciene, 2012).

Cloud computing services are generally divided into three separate categories or levels (KMPG, 2012):

1)Infrastructure as a Service (IaaS) is the lowest level. Renting access to computer processing power and storage over networks.

2)Platform as a service (PaaS) is the next level up. Developing and hosting bespoke software in cloud environments (platforms) that provide all required tools, languages, databases, and resources.

3) Software as a Service (SaaS) is the highest level of the cloud computing service. Renting access to software as web-accessed services instead of installing it on the premises.

According to the way these services deploy, there are four cloud computing deployment models (Mell \& Grance, 2011; Attaran \& Woods, 2018): (1) Public cloud. Cloud infrastructure is made available to the general public and all cloud services are available in an on-demand manner. It is owned, and exists on the premises of the cloud provider (third-party organization). Customers pay only for the CPU, storage, or bandwidth they consume.

(2) Private cloud. Private cloud infrastructure is provisioned and run exclusively for one organization. It may be owned, managed, and operated by the organization or by the cloud provider. The infrastructure may exist on or off-premises. Private clouds provide a high level of security and better control over the cloud infrastructure, which makes them more expensive than public clouds. (3) Community cloud. The cloud infrastructure is provisioned for exclusive use by a specific community of consumers from organizations that have the same requirements (such as mission, policy, performance, security, and compliance requirements). It may be owned, managed, and operated by one or more of the organizations in the community, 
the cloud provider, or some combination of them. It may exist on or off-premises. (4) Hybrid cloud. Hybrid cloud combine two or more distinct cloud infrastructures - private, community, or public, bound together by technology that allows data and applications to be shared between them. A public cloud is used for non-critical information, while sensitive information is kept on a private cloud controlled by the organization. This cloud structure gives business flexibility, more deployment options, optimize security and compliance requirements.

Cloud-based AIS can integrate all the critical information needed for accounting processes within the same system and enables the various parties to access cloud-based AIS (such as client company, accountant, and auditor) to have the opportunity to work simultaneously on the real-time accounting process, in a transparent manner. Cloud accounting can be advantageous in many ways in today's business world. The potential impact of cloud computing on the accounting information system when applied is revolutionary, especially in the way AIS collect and store data about activities and transactions; process data into useful information for making decisions; and provide adequate controls to safeguard the organization's assets. According to Khanom (2017) and Al-zoubi (2017), the potential benefits of cloud computing in the field of accountancy and elements of AIS are summarized as follows: - Less costs. It allows individuals and firms to use software and physical equipment without the need to make a lump-sum purchase of a program, or buy and set up a server to host it.

- 24/7 Accessibility to All Accounting Information. Users can get all the financial reports provided by the established system at any time and any place according to the powers granted by the company to its users and so information from AIS can no more be delayed.

- Real-Time Information Updating. When new data is entered, it populates each location where it is required. Accountants on the cloud can do mobile accounting by approving transactions; authorizing payments; enter financial data; preparing financial statements.

- Security of Financial Information. There are a set of policies, controls, procedures, and technologies that work together to protect cloud-based systems, data, and infrastructure.

- Scalability. Every piece of infrastructure can be expanded to handle increased load. Scalability can be applied to: Disk, Memory, Network, CPU, etc.

- Automatic Data Back-Up and Restoration. This helps to secure the information in the event of a break-in, fire, or other incidents that could put sensitive and important information at risk.

- Automatic Software Updates. It adds new software that is simple and easy to use.

\section{ARTIFICIAL INTELLIGENCE AND THE FUTURE OF AIS}

Job description of today's accountant looks very different than that accountant 20 years ago. In another 20 years, accountants will again, play a different role. The roles of accountants and the way how accounting information flow will change substantially over the next decade. Accountants will need to embrace specialization and the use of Artificial Intelligence as ongoing technology. Artificial Intelligence (AI), also called Machine Intelligence, could be simply defined as any machine or device which has the human ability to think, learn, solve problems and take decisions (Rane \& Lahane, 2020). AI is a computer program to think and learn, with the main goal to provide software that can solve specific tasks, efficiently and effectively process the inputs into outputs, and alter required specific methodologies, information analysis, report preparation, and many cumbersome processes, without being encoded with commands. Accountancy, Accounting Information specifically is a field that AI has already been applied and is increasingly developing in the automation of the elements of the Accounting Information Systems (eg. save, retrieve, store, process, and analyze the firm's financial data). According to a study done by the Association of Chartered Certified Accountants, there is a possibility that automation will relieve many burdensome tasks that would enable accountants to focus on consulting services and other higher-value work. 
Artificial intelligence is particularly applicable and with automation can replace routine tasks like accounting (bookkeeping), audit, taxation, analysis and calculation of indicators etc. In the era of artificial intelligence, with the popularization of intelligent accounting software, accounting presents the characteristics of intelligence and automation. The focus of accounting work has shifted to analysis, judgment, decision-making, management, and so on (Guo, 2019). The primary issue with bookkeeping is manual and repetitive data entry which makes the process tedious. It makes it less attractive for generations to come. Lack of competence, human error, unexpected life events, and lack of scalability makes humans inefficient in bookkeeping. According to research done by the University of Oxford in 2015, accountants have a 95\% chance of losing their jobs as machines take over the role of data analytics and number crunching. In the era of AI, the New Management Accounting Theory believes that financial personnel still have a good space for survival and development (Li et al., 2020). This requires accountants to actively change their ideas and to understand and be prepared to work alongside artificial intelligence. Accountants need high quality, comprehensive, and timely financial and non-financial information and analysis to help and support businesses and stakeholders to make better decisions.

AI is critical to the future of the accounting and auditing professions. AI is a vital tool that will provide these professionals with the needed tools to increase the efficiency and effectiveness of their occupations (Baldwin \& Trinkle, 2006):

- The presentation of accounting information can automatically generate accounting statements, which is helpful for staff to obtain dynamic accounting information in real-time (Guo, 2019). With AI-based accounting software, any document can be scanned and the relevant information is sorted and stored categorically to allow easier analysis of the same. It generates new insights from the analysis of data and provides better and cheaper data to support decision-making.

- The monthly, quarterly, or yearly closing procedures can be automated with an Artificial Intelligence system and thereby significantly reduce the amount of time spent on such activities. It will help in making such information available to the management immediately after the closing date. AI systems can also efficiently work to create reserves of funds for timely payment of such expenses thereby supporting Working Capital management and give proper priority to the expenses based on their nature and frequency (Rane \& Lahane, 2020).

- They can process huge amounts of data (structured and unstructured), and pick up weaker or more complex patterns in data than humans can. They also do not exhibit human biases and therefore provide opportunities to eliminate cognitive biases, so can be more consistent decision-makers.

- AI using machine learning can make better predictive models to forecast revenues and expenses and increases the scope of control in the process of accounting and finance (Icaew IT Faculty, 2018).

- Improving fraud detection through more sophisticated, machine learning models of 'normal' activities and better prediction of fraudulent activities. A business can keep a categorized record of the spending and at the same time easily audit the same for various non-compliances as well as for any possible frauds.

\section{THE IMPACT OF COVID-19 ON AIS}

The ongoing COVID-19 crisisis affecting the accounting profession as well as all professions. Its effects are contained in a way that generate, collect, analyze and interpret accounting information. One area in which the Covid 19 crisis could have a major impact is the internal control process. Accountants should be cautious about the threats and risks that may arise as a result of Covid 19. The following list of program areas is not exhaustive, but it highlights where 
additional attention may be required (Deloitte, 2020): 1. Scoping and risk assessment. Performing a tailored risk assessment, including review of the principles and points of focus in the COSO 2013 framework in light of changes, should be completed. Scoping and risk assessment conclusions should be revisited to verify that they reflect the current reporting period's organizational risks. Specifically, the following process areas may have increased risk: Revenue, supply chain, technology and other infrastructure disruption; Processes that are reliant on select few resources (e.g., highly technical areas, estimates, and significant judgments) and may require updates to delegation of authority; Processes that are highly manual; Areas that are susceptible to fraud (e.g., money movement). 2. The design of controls may need to be adjusted (as well as appropriate documentation of the adjustment maintained) to compensate for changes in risk, or contingency plans may need to be put in place for outsourced service providers. 3. Evaluation of the operating effectiveness of controls may need to include a plan for increased levels of remote testing. This will likely also result in an increased focus on the quality of documented evidence to support the evaluation of the operating effectiveness of controls, in particular a management review control where judgment is used by testers to evaluate the sufficiency of the documentation to support a conclusion that the control is operating effectively. 4. Changes in workforce, remote working and in the business as a result of COVID-19 may increase control deficiencies. Management will need to put in place plans for a timely and effective response. This will require careful project management and put increased pressure on those individuals with the best knowledge of internal control. 5. Typical communication plans with senior management and board members may need to be revisited, so that they are given the information they need on a timely basis to fulfil their responsibilities.

\section{RESEARCH METODOLOGY}

The world of accounting is subject to change due to the evolution of the field of computer science. In this regard, this study focuses on the analysis of leading information technologies that have an impact on AIS. On the other hand, it assesses practitioners' perceptions of these technologies by analyzing their level of awareness and knowledge about Big Data, Blockchain, Cloud Computing, Artificial Intelligence, and related security challenges. This empirical study aims to find out whether certified professional accountants in the Republic of North Macedonia have a sufficient level of understanding of new technologies along with related benefits and challenges in the field of AIS, as well as to examine their perception of the role and impact of these technologies on AIS. For that purpose, we designed a survey aimed at practitioners working in the field of domestic accounting and auditing practice.

\subsection{Sample characteristics}

The questionnaire included 16 questions that focused on the professional activity of practitioners, their perception of new technologies, and the associated risks posed by the new situation with COVID-19. Most of the questions were answered on a Likert scale from 1 to 5 where 1 totally disagrees and 5 totally agrees. The survey was sent to 150 practitioners (accountants, auditors, and academics) in the Republic of North Macedonia. Participants received an email with a link to the questionnaire and 57 responses are received or a response rate of $38 \%$. Professional field of the participants is presented in Table 1. 
Table 1: Professional field of the participants

\begin{tabular}{lr}
\hline Professional field & No. of participants \\
\hline Accounting & $14(24,6 \%)$ \\
Audit & $36(63,2 \%)$ \\
Academia & $7(12,3 \%)$ \\
TOTAL & $\mathbf{5 7}(\mathbf{1 0 0 \% )}$ \\
\hline
\end{tabular}

(Source: Authors calculations)

\section{RESULTS AND DISCUSSIONS}

Prior to any research analysis of the results, an analysis of the reliability of the responses was performed. In order to measure the internal consistency and reliability of the questionnaire, the Cronbach's alpha coefficient was calculated. Its score is $\mathbf{0 , 8 3}$ which means high internal consistency, and all items seem worthy of retention.

The first introductory questions, Q2 and Q3 refer to the knowledge of technologies by the respondents, and whether they are applied in their companies.In both questions they had the chance to answer more than one answer, according to the nature of the questions. Cloud Computing is the most familiar technology between practitioners $(59,6 \%)$ and also $43,9 \%$ of them are actively using this technology, so it is the most dominant technology according this questionnaire. Big data is also known between the practitioners $(43,9 \%)$, and $15,8 \%$ of them are actively using it. Blockchain and Artificial Intelligence are less known between the participants in this questionnaire with $29,8 \%$ each, but on the second question, the results shows that only $7 \%$ of the participants are using Blockchain and 3,5\% of the participants are using Artificial Intelligence. 28,1\% are related to option - None in the first question, which means that they don't know the characteristics of these technologies, and in the second question the option - None counts $52,6 \%$, that means in our domestic practice there is very poor practical use of these technologies.

Regarding Big Data, some of the large companies in the world already classify them as an asset in the Balance Sheet. Most of the participants generally think that Big Data should also have the same treatment in domestic practice. Participants also believe that the application of Big Data can reduce subjective estimates in determining fair value. The results of these responses are presented in more detail in Table 2.

\section{Table 2: Big Data}

\begin{tabular}{|c|c|}
\hline$Q 4$. & $\begin{array}{l}\text { In regards of Big Data, some of the large companies in the world already classify them as } \\
\text { an asset in the Balance Sheet. How much do you agree with this treatment and do you } \\
\text { think that it should be applied in domestic practice? (Likert skale) }\end{array}$ \\
\hline Results & $\begin{array}{llllllll}1-7(12,3 \%) & 2-5(8,8 \%) & 3- & \begin{array}{l}19 \\
(33,3 \%)\end{array} & 4- & \begin{array}{l}10 \\
(17,5 \%)\end{array} & 5-16(28,1 \%) \\
\end{array}$ \\
\hline$Q 5$ & $\begin{array}{l}\text { One of the many benefits of Big Data in AIS is the ability to mitigate subjective estimates } \\
\text { in determining the fair value of a particular element in the financial statements. How much } \\
\text { do you agree with this statement? (Likert skale) }\end{array}$ \\
\hline Results & $\begin{array}{ll}4- & 19 \\
& (33,3 \%) \\
\end{array}$ \\
\hline
\end{tabular}

(Source: Authors calculations)

The blockchain operates in a decentralized manner, with no central authority validating the transactions, which are validated by consensus by all participants. Regarding the reliability of the transactions generated in this way, most of the respondents think that they can have an adequate level of confidence in the integrity of the transactions. Also, the respondents believe 
that the reduction of costs $(73,7 \%)$ is the biggest benefit from the application of Blockchain in the operation, while reducing the need to use a sample in the audit is perceived as the least benefit $(8,8 \%)$. Table 3 summarizes the results of these responses.

\section{Table 3: Blockchain}

Q6. Blockchain technology operates in a decentralized manner, i.e. there is no central authority, as an intermediary, which would validate the transactions entered by the participants in the network. Do you think this kind of operation provide an adequate level of confidence in the integrity of the transactions? (Likert skale)

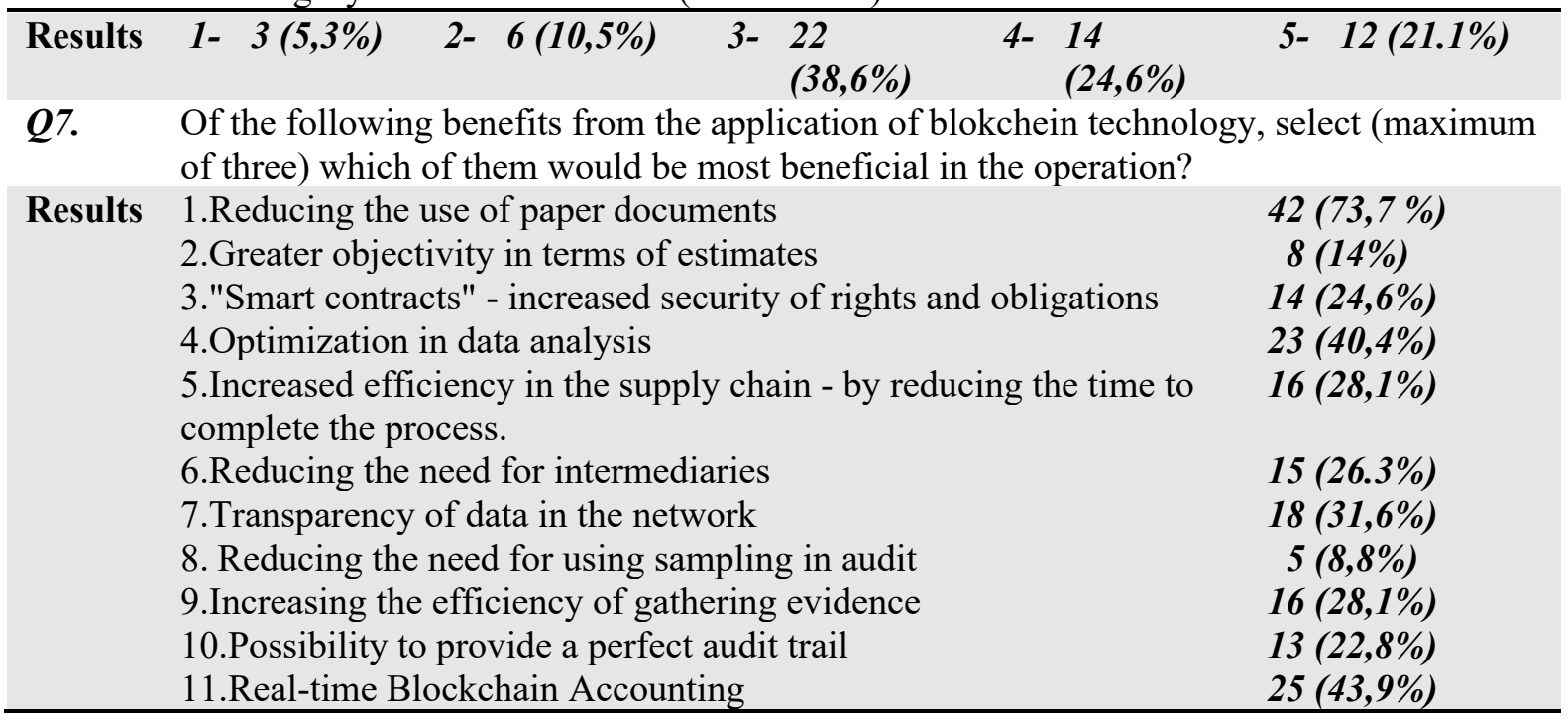

(Source: Authors calculations)

Cloud Computing technology reaches a great depth into everyday accounting practice and directly affects the way accounting information circulate. The greatest benefit from this technology according to the participants is the flexible accessibility - 24/7 access to all accounting informationfrom any place on any device based on Internet. Cost savings for Hardware, Software and IT maintenance is also great benefit that $22,8 \%$ of the participants voted for it. $42,8 \%$ of the participants in the question concerning about the biggest threat and constraint that affect the implementation and the use of Cloud Computing technology in AIS chose Skepticism about the security and protection of sensitive data, which means that they still are not $100 \%$ ready to believe and share the sensitive data to system or someone other than them. Most of the participants think that cloud computing technology will improve the application performance of AIS with $63,8 \%$ votes for agree and strongly agree. Table 4 gves more details about these questions.

\section{Table 4. Cloud Computing}

Q8. Which of the following benefits of cloud computing technology do you think is most beneficial to accounting information systems?

\begin{tabular}{|c|c|c|}
\hline Results & $\begin{array}{l}\text { 1. Cost savings. } \\
\text { 2.24/7 access to all accounting information. } \\
\text { 3. Scalability. } \\
\text { 4. Security of financial information. } \\
\text { 5.Automatic backup and data recovery. }\end{array}$ & $\begin{array}{c}13(22,8 \%) \\
24(42,1 \%) \\
3(5,3 \%) \\
7(12,3 \%) \\
10(17,5 \%)\end{array}$ \\
\hline Q9. & $\begin{array}{l}\text { Which of the following constraints (threats) } \\
\text { you consider to be the greatest barrier to its a } \\
\text { systems? }\end{array}$ & $\begin{array}{l}\text { technology do } \\
\text { ormation }\end{array}$ \\
\hline Results & 1.Integration into the existing system. & $9(15,8 \%)$ \\
\hline
\end{tabular}




\begin{tabular}{|c|c|c|}
\hline & $\begin{array}{l}\text { 2.The company policy and the lack of complete control by the } \\
\text { company. }\end{array}$ & $7(12,3 \%)$ \\
\hline & 3. Skepticism about the security and protection of sensitive data. & $24(42,1 \%)$ \\
\hline & $\begin{array}{l}\text { 4. Possible incompatibility of cloud services in the internal process of } \\
\text { the organization. }\end{array}$ & $7(12,3 \%)$ \\
\hline & 5. Necessary fast and stable Internet connection. & $10(17,5 \%)$ \\
\hline$Q 10$. & $\begin{array}{l}\text { How much do you think the implementation of cloud computing tech } \\
\text { improve the application performance of accounting information syste }\end{array}$ & $\begin{array}{l}\text { ology will } \\
\text { ns? (Likert skale) }\end{array}$ \\
\hline Results & $\begin{array}{lllll}1-0(0 \%) & 2-2(3,5 \%) & 3-\begin{array}{l}19 \\
(33,3 \%)\end{array} & 4-\begin{array}{l}20 \\
(35,1 \%)\end{array}\end{array}$ & $16(28,1 \%)$ \\
\hline
\end{tabular}

(Source: Authors calculations)

Participants were asked about Artificial Intelligence and its application in AIS. On the question for how much they agree that the process of circulating accounting information can be automated, most of the participants (57,9\%) agree or strongly agree to this. Only $8,8 \%$ disagree and none of them exposed strongly disagree reaction. In question 12 participants had different opinions (see Table 5) on whether AI can replace human factor and does Machine learning is better than Human learning. Question 13 concerns about the trust and confidence in the information generated and interpreted by AI, and also if are they willing to accept them as part of the daily operations. Participants also have different opinions, but with positive trend of trust (see Table 5). From these results we can see that practitioners in domestic practice are still skeptic and they need more time so they can relay on automation process and implementing AI in AIS.

Tabel 5. Artificial Intelligence

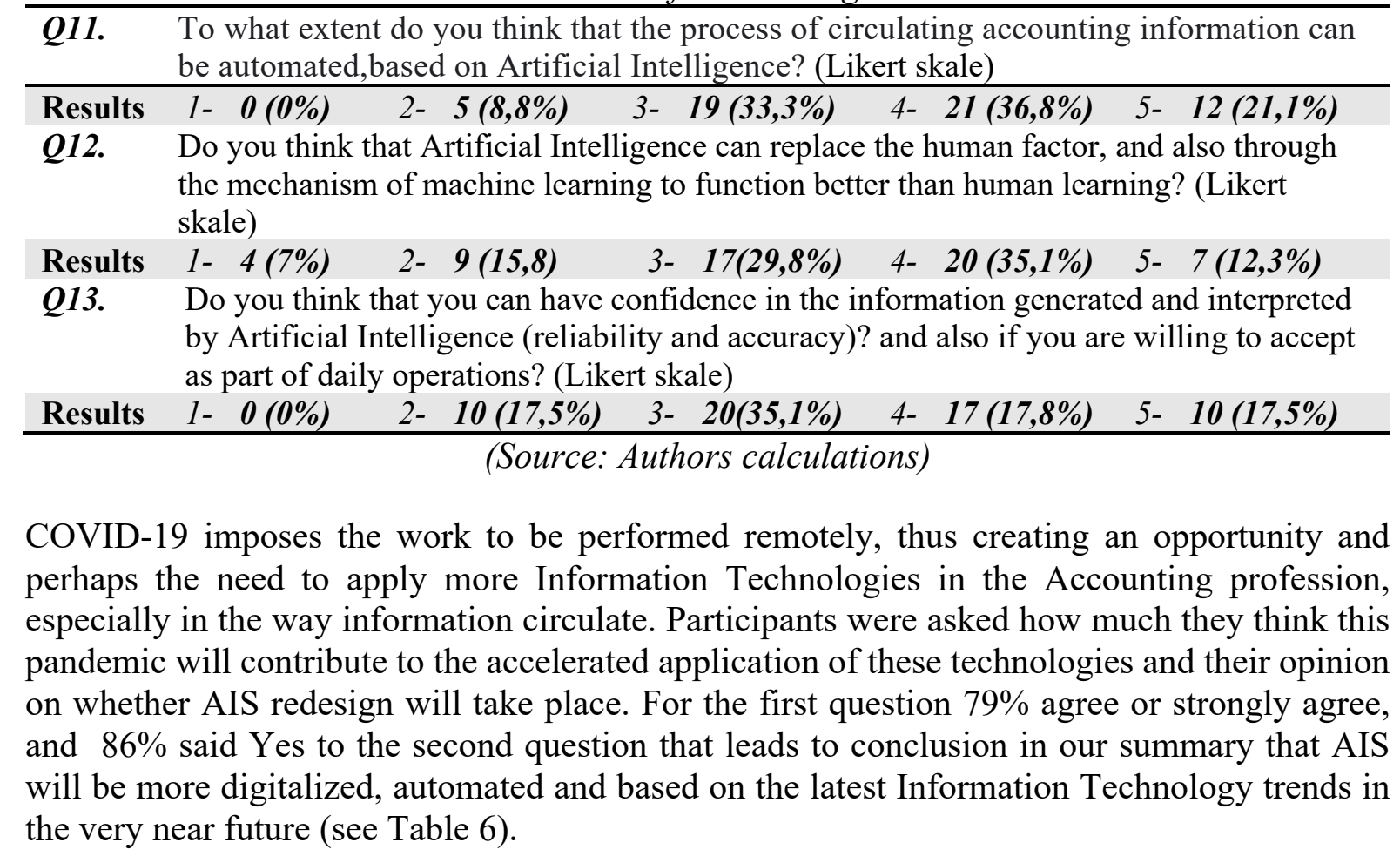


Table 6. Impact of COVID-19 on AIS

Q14. How much do you think that the new situation with the COVID 19 crisis will contribute to the accelerated application of these technologies? (Likert skale)

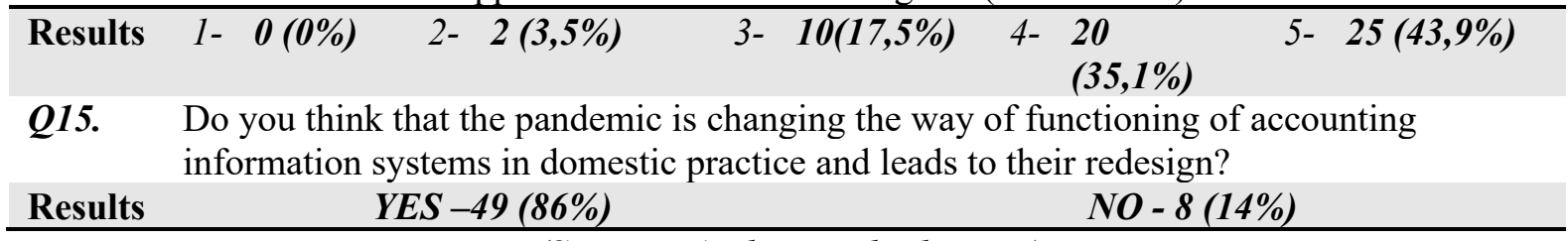

(Source: Authors calculations)

The last question in this questionnaire was related to preference and choice of the participants for these technologies. They had the chance of choosing maximum two, so we find out that in domestic practice Cloud Computing with $71,9 \%$ and Big Data with 50,9\% will be the most dominant technologies in practical application. The details are presented in Figure 1.

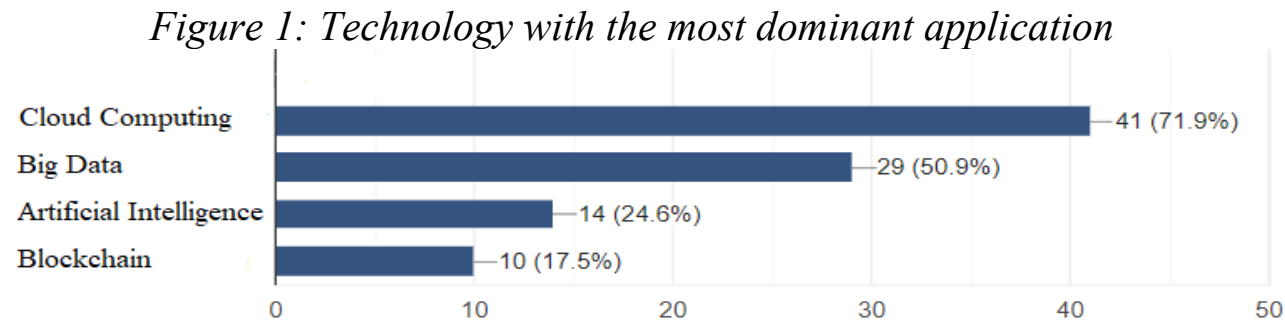

(Source: Authors calculations)

\section{CONCLUSION}

The digitalization process is changing dramatically the accounting profession. New technologies are changing the focus of the profession, that is, the routine work of accountants has now been replaced by technology. The automation process contributes to reducing the role of people as an element in AIS. The benefits of these technologies, which were elaborated earlier, are enormous, that is, they shorten the time it takes for accountants to perform their tasks, and therefore make them more efficient. Big data significantly reduces data analytics time, unlike traditional data analysis and processing software. Blockchain technology allows accountants to store digital information in a public database. Blockchain is the most common application of Distributed Ledger Technology (DLT), which uses cryptographic tools and a distributed consensus process to create a significant innovation in traditional record keeping. The increasing flow of accounting information is not sufficiently effective and efficient in traditional accounting information systems, so accountants have to master and use cloud computing technology, which is particularly applicable to small and mediumsized companies, and large companies that want to provide a better, lighter and more economical work. And, last but not least, Artificial Intelligence as technology changes the work of accountants, so that all continuous and repetitive work is automated. That does not mean completely replace human beings as a factor, but rather taking advantage of these benefits, accountants need to commit to more complex tasks such as analysis, projections, interpretations and help the company to meet its objectives. According to the results obtained from the survey conducted among practitioners in the Republic of North Macedonia, Cloud Computing and Big Data are the best known and most commonly used technologies in practical application on AIS. Artificial Intelligence and Blockchain as technologies are poorly implemented and insufficiently known in domestic practice due to the nature of the work in our country, the lack of advanced IT companies and the level of country development. The use 
of these technologies is increasingly evident, and even necessary, which is particularly evident in the current state of the COVID-19 Pandemic.

\section{REFERENCES}

Abbasi, A., Sarker, S., and Chiang, R. (2016), "Big Data Research in Information Systems: Toward an Inclusive Research Agenda", Journal of the Association for Information Systems, 17(2), 1-32.

ACCA\&IMA. (2013). Big data: its power and perils.

ACCA\&IMA. (2013). Digital Darwinism: thriving in the Face of Technology Chance.

AccountingEdu. (2020). What are Accounting Information Systems? Retrieved June 1, 2020, from AccountingEdu Web site: https://www.accountingedu.org/accounting-informationsystems.html

Al-zoubi, A. (2017). The Effect of Cloud Computing on Elements of Accounting Information System. Global Journal of Management and Business Research: D Accounting and Auditing, 17(6), 1-9.

Anwar, H. (2019, November 16). The Ultimate Guide to Pros and Cons of Blockchain. Retrieved June 20, 2020, from 101 Blockchains - Enterprise Blockchain Research \& Training: https://101blockchains.com/pros-and-cons-of-blockchain/\#prettyPhoto

Armbrust, M., Stoica, I., Zaharia, M., Fox, A., Griffith, R., Joseph, A. D., et al. (2010). A View of Cloud Computing. Communications of the ACM, 53(4), 50-58.

Attaran, M., \& Woods, J. (2018). Cloud Computing Technology: Improving Small Business Performance Using the Internet. Journal of Small Business \& Entrepreneurship, 13(2), 94-106. Baldwin, A., E., B., \& Trinkle, S. (2006). Opportunities for Artificial Intelligence Developmrnt in the Accounting Domain: The Case for Auditing. Intelligent Systems in Accounting Finance\&Management, 14(3), pp. 77-86.

Belfo, F., \& Trigo, A. (2013). Accounting Information Systems: Tradition and Future Directions. CENTERIS 2013 - Conference on ENTERprise Information Systems / PRojMAN 2013 - International Conference on Project MANagement / HCIST 2013 - International Conference on Health and Social Care Information Systems and Technologies (pp. 536-546). Lisbon: Elsevier Procedia.

Bhimani, A., \& Willcocks, L. (2014). Digitisation, 'Big Data' and the transformation of accounting information. Accounting and Business Research, 44(4), 469-490.

Chartered Accountants A\&NZ. (2017, February 1). The Future of Blockchain: Chartered Accountants A\&NZ. Retrieved May 8, 2020, from Chartered Accountants A\&NZ Web site: https://www.charteredaccountantsanz.com/news-and-analysis/insights/research-and-

insights/the-future-of-blockchain

Christauskas, C., \& Miseviciene, R. (2012).Cloud-Computing Based Accounting for Small to Medium Sized Business. Engineering Economics, 23(1), 14-21.

Corkern, S., Kimmel, S., \& Morehead, B. (2015). Accountants Need To Be Prepared For The

Big Question: Should I Move To The Cloud? International Journal of Management\&Information Systems, 19(1), 13-20.

CPA Canada. (2019). Big Data and Artificial Intelligence - The Future of Accounting anf Finance. CPA Canada.

Dai, J., \& Vasarhelyi, M. (2017). Toward Blockchain-Based Accounting and Assurance. Journal of Information Systems, 31(3), 5-21.

Deshmukh, A. (2006). A Framework for Digital Accounting. In A. Deshmukh, Digital Accounting: The Effects of the Internet and ERP on Accounting (pp. 1-14). IRP Press.

Dimitriua, O., \& Mateia, M. (2015). Cloud accounting: a new business model in a challenging context. Emerging Markets Queries in Finance and Business, (pp. 665-671). 
Dynamic Markets. (2012). Data and the CFO: A Love/Hate Relationship. Retrieved May 30, 2020, from SAS Web site: http://www.exist.com/blog/5-faqs-about-big-data\#.UnfoRvnIa0Q Franks, B. (2012). Taming the Big Data Tidal Wave: Finding Opportunities in Huge Data Streams with Advanced Analytics. New York: Wiley.

Frøystad, P., \& Holm, J. (2020). Blockchain: Powering the Internet of Value. Retrieved June 13, 2020, from Fineyear: https://www.finyear.com/attachment/637653/

Guo, X. (2019). Research on the Transition from Financial Accounting to Management Accounting under the Background of Artificial Intelligence. Journal of Physics: Conference Series 1345042031.

Hall, J. A. (2011). Accounting Information Systems (7th Edition ed.). South Western Educational Publishing.

Hall, J. A. (2019). Accounting Information Systems (10th Edition ed.). Cengage Learning.

Hoffman, C. (2017, 6 28). Accounting and Auditing in the Digital Age. Retrieved from http://xbrlsite.azurewebsites.net/2017/Library/AccountingAndAuditingInTheDigitalAge.pdf

Hong Kong Institute of CPA. (2017, October 26). Big data, big impact of accounting. Retrieved May 26, 2020, from A Plus: https://aplusmag.goodbarber.app/topics/c/0/i/17867251/big-databig-impact-accounting

Icaew IT Faculty. (2018). Artificial Intelligence and the Future of Accountancy. Icaew.

Inghirami, I. (2019). Accounting Information Systems in the Time of Blockchain. itAIS 2018 Conference (pp. 1-15). Pavia: University of Pavia.

Khanom, T. (2017). Cloud Accounting: A Theoretical Overview. IOSR Journal of Business and Managemen, 19(6), 31-38.

Khun, R., \& Sutton, S. (2010). Continuous Auditing in ERP System Environments: The Current State and Future Directions. Journal of Information Systems, 24(1), 91-112.

KMPG. (2012). Modeling the Economic Impact of Cloud Computing. Australian Information Industry Association.

Lasi, H., Fettke, P., Kemper, G., Feld, T., \& Hoffmann, M. (2014). Industry 4.0. Business\&Information Systems Engineering, 6(4), 239-242.

Li, C., Haohao, S., \& Ming, F. (2020). Research on the Impact of Artificial Intelligence Technology on Accounting. Journal of Physics: Conference Series 1486032042.

Marr, B. (2018, 9 2). What is Industry 4.0? Here's A Super Easy Explanation For Anyone. Retrieved June 19, 2020, from Forbes: https://www.forbes.com/sites/bernardmarr/2018/09/02/what-is-industry-4-0-heres-a-supereasy-explanation-for-anyone/\#748c8c509788

Mell, P., \& Grance, T. (2011). The NIST Definition of Cloud Computing. Gaithersburg: National Institute of Standards and Technology.

Miraz, M., \& Ali, M. (2018). Applications of Blockchain Technology beyond Cryptocurrency. Annals of Emerging Technologies in Computing (AETiC), 2(1), 1-6.

Moffitt, K., \& Vasarhelyi, M. (2013). AIS in an Age of Big Data. Journal of Information Systems, 27(2), 1-19.

Patrizio, A. (2018, March 27). Top 10 Blockchain as a Service Providers. Retrieved June 14, 2020, from Datamation: https://www.datamation.com/data-center/top-10-blockchain-as-aservice-providers.html

Peters, G. W., \& Panayi, E. (2016). Understanding modern banking ledgers through blockchain technologies: Future of transaction processing and smart contracts on the Internet of Money. In P. Tasca, T. Aste, L. Pelizzon, \& N. Perony, Banking Beyond Banks and Money (pp. 239278). New York: Springer International Publishing.

Potekhina, A., \& Riumkin, I. (2017, June 6). Blockchain-a new accounting paradigm: Implications for credit risk management. Retrieved June 14, 2020, from Diva-portal: http://www.diva-portal.org/smash/record.jsf?pid=diva2\%3A1114333\&dswid=7579 
Rane, P., \& Lahane, B. (2020). The Future of Accounting an Finance: Artificial Intelligence. 40(38), 297-304.

Reiff, N. (2020, February 1). Blockchain Explained:Investopedia. Retrieved May 08, 2020, from Investopedia Web site: https://www.investopedia.com/terms/b/blockchain.asp

Romney, M. B. (2018). Accounting Information Systems (14th Edition ed.). Harlow: Pearson Education Limited.

Rowe, O. (2019, December 1). The pros and cons of blockchain adoption. Retrieved June 20, 2020, from Financial Management magazine: FM: https://www.fmmagazine.com/issues/2019/dec/blockchain-pros-and-cons.html

Swan, M. (2015). Blockchain: Blueprint for a New Economy. Sebastopol:O'Reilly Media.

Syed, A., Gillela, K., \& Venugopal, C. (2013, June). The Future Revolution on Big Data. International Journal of Advanced Research in Computer and Communication Engineering, 2(6), 2446-2451.

Tapscott, D., \& Tapscott, A. (2016). Blockchain revolution.New York: Portfolio-Penguin.

Tysiac, K. (2017, November 17). Blockchain: An opportunity for accountants? Or a threat? Retrieved June 14, 2020, from Journal of Accountancy: https://www.journalofaccountancy.com/news/2017/nov/blockchain-opportunity-foraccountants-201717900.html

Visiongain. (2013). World Big Data Market Opportunities 2013-2018:Converging Data Architectures. London: Visiongain Global. 